\title{
Exploring the determinants of intention to use self-checkout systems in super market chain and its application
}

\author{
Ufuk Cebeci $^{a^{*}}$, Abdullah Ertug ${ }^{\mathrm{b}}$ and Hulya Turkcan ${ }^{\mathrm{c}}$
}

${ }^{a}$ Istanbul Technical University, Turkey

${ }^{b}$ Migros Research \& Development Center, Turkey

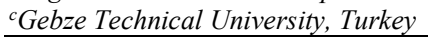

\section{H R O N I C L E}

Article history:

Received: September 212019

Received in revised format: Octo-

ber 282019

Accepted: November 3, 2019

Available online:

November 7, 2019

Keywords:

Self-Checkout System

Technology Acceptance Model

Cashier-less payment

Perceived usefulness

Super market

\section{A B S T R A C T}

Technology and innovativeness have played an important role in service industries because of the competitive state, especially in developing countries. While using innovative technologies such as self-checkouts in stores is seen as advantageous in many aspects for retailers, if customers cannot adopt it, the usage of in stores becomes disadvantageous. However, the literature offers limited knowledge about the customers' adoption of self-checkouts in spite of its value for the survival of firms. Therefore, understanding what factors affect individuals' intention to use self-checkout systems has been a need for both practitioners and researchers. This study aims to spot out the determinants of intention to use self-checkout systems in a supermarket chain. In this regard, this study employs the technology acceptance model (TAM) to which the constructs technology anxiety, technology self-efficacy, compatibility, and knowledge are incorporated into the original model. The results of the analysis of the data $(\mathrm{N}=281)$ reveals that: (i) technology self-efficacy and knowledge are positively related to two beliefs, perceived ease of use and perceived usefulness, (ii) compatibility is positively associated with perceived usefulness, (iii) perceived usefulness is positively related to attitude, and (iv) attitude is positively associated with intention to use.

\section{Introduction}

Rapid developments in technology have changed greatly on how retailers offer services to consumers. Since, innovation and new technology usage have not been only a requirement for profitability, but also for survival and sustainability due to the competitive environment (Bulmer, Elms, \& Moore, 2018). Therefore, retailers need to implement new technologies and innovative ways of offering services. Accordingly, these services are now becoming more technological as a natural consequence of the rapid spread of self-service technologies (Liu, 2012) and the desire of retailers to reduce costs, enhance value and increase customer satisfaction (Orel, \&Kara, 2014). Self-service technologies can be defined as "technological interfaces that enable customers to produce a service independent of direct service employee involvement" (Meuter, Ostrom, Roundtree, $\&$ Bitner, 2000). As a result of self-service technologies, which are becoming more and more widely used, customers are confronted with the technologies they can get service without having direct interaction with an employee (Curran, Meuter, \& Surprenant, 2003). The self-checkout system is a type of the self-service technologies customers faces (Meuter, Ostrom, Roundtree, \& Bitner, 2000). Self-scan checkouts are an example of innovative self-service technology. They are checkouts where customers scan the barcodes of their products, pay for the products and put them into bags on their own, without the help of service employees. (Schliewe and Pezoldt, 2010). The self-checkout system is an innovative self-service technology which provides time-saving and privacy to customers as an alternative way to cashier-staffed checkout (Lee, \&Yang, 2013). Due to the many benefits provided to the retailer and customers, customers day by day accept self-checkout systems (Leung, \&Matanda, 2013) and the retailers' use of self-checkout systems is increasing (Orel, \&Kara, 2014). Therefore, it is important to examine the factors affecting the adoption of self-checkout systems by customers. In this way, firms may identify ways to increase the use of them (Leung, \& Matanda, 2013). Furthermore, the implementation of new technology for firms is both

* Corresponding author.

E-mail address: cebeciu@itu.edu.tr (U. Cebeci) 
time-intensive and cost-intensive. It is another reason to need deep knowledge about the determinants of acceptance of new technology (Schliewe and Pezoldt, 2010). Researchers have been showed great interest in their studies which investigate the acceptance of self-service technologies; however, it is very limited for self-checkout systems, in particular.

Past research examined several factors which affect the adoption of self-service technologies such as order size, wait-time tolerance, location convenience, employee presences (Collier, Moore, Horky, \& Moore, 2015), self-determined motivation (Leung, \& Matanda, 2013), personal values (Lee, \& Lyu, 2016), and satisfaction (Liu, 2012). But although TAM is the most useful and commonly used model to predict the acceptance of innovative technologies (Chen, Gillenson, \& Sherrell, 2002), there are very few empirical research on the factors that influence the acceptance of self-service technologies by using TAM (Weijters, Rangarajan, Falk, \& Schillewaert, 2007; Oghazi, Mostaghel, Hultman, \& Parida, 2012; Kallweit, Spreer, \& Toporowski, 2014). Moreover, it is observed that there has been no study in which TAM is used to explore the acceptance of self-checkout systems. In response to this need, this paper focus on examining the determinants of intention to use selfcheckout systems by using TAM as a basis. Although TAM is a model that has been used the most in past relevant research and explains the variance of intention to use significantly (Venkatesh, \& Davis, 2000), the original model of TAM considers the customers as passive audiences driven by the features of the new technology (Leung, \&Matanda, 2013). However, the self-checkout system is an innovative technology offered a payment preference to customers and allow them to be more active and empower them in purchasing processes. In this respect, it is crucial to identify customer related features such as specifications, technology knowledge, and capabilities that may affect the acceptance of the self-checkout system to understand it deeply and extensively. For this necessity, based on theory and related literature and by taking into consideration the nature of self-checkout systems, exploration the possible determinants of original TAM such as technology anxiety (Schliewe, \& Pezoldt, 2010; Liu, 2012; Larson, 2019), self- efficacy (Schliewe, \& Pezoldt, 2010; Wang, Harris, \& Patterson, 2013), knowledge (Bulmer, Elms, \& Moore, 2018; Larson, 2019), and compatibility (Kim, \& Qu, 2014; Bulmer, Elms, \& Moore, 2018) is also essential.

For firms in developing countries compared with firms in developed countries, innovations and innovative technologies are much more important, to create new markets and to take part in existing markets (Chipp, Hoenig, \& Nel, 2006). Because in developing countries, the industry has a highly competitive and dynamic (Akour, \& Dwairi, 2011). Because of the competition, it is crucial to find new innovative solutions for the customers. However, the implementation of innovative technologies is cost-intensive and time-intensive (Schliewe, \& Pezoldt, 2010). Since it is more important to know what the factors affect customers' acceptance of new technology for these firms. On the other hand, individuals in developed countries are faced with innovative technologies frequently and so accustomed to new technologies easily. Therefore, the research in developing countries may provide further knowledge about the adoption of innovative technologies such as self-checkout systems. By taking into consideration these gaps, the purpose of this study is to examine the determinants of intention to use self-checkout systems based on TAM. Despite the wide range of studies using the TAM model, this study focuses on self-checkout systems in particular. Also, the research is conducted in Istanbul which is the largest city in Turkey as a developing country. Therefore, our findings will contribute to TAM literature. Another goal is that this study provides a comprehensive examination and assessment on factors affecting the adoption of self-checkout systems by incorporating the possible determinants arising from related literature and nature of self-checkout systems into original TAM. By putting forward the factors that enable the adoption of the self-checkout systems, it will be possible to both understand the causes of individuals who exhibit resistance and improve its usage. Thus, some steps will be clarified to increase the effective use of technology in service offered by retailers and in turn increase service quality.

This paper proceeds as follows. First, the theoretical background is presented and hypotheses are developed. Next, research methodology is outlined and findings are described. In the latter section, discussion and implications are expressed. In the penultimate section, limitations are remarked and future research directions are suggested. Finally, the conclusion is offered.

\section{Theoretical background and hypothesis development}

\subsection{Technology Acceptance Model}

There have been some researches to understand the factors which can have an impact on the adoption of new technology. The models establishing in these researches are Theory of Reasoned Action (TRA) (Fishbein \& Ajzen, 1975), Theory of Planned Behavior (TPB) (Ajzen, 1991), Technology Acceptance Model (Davis, 1989), and Unified Theory of Acceptance and Use of Technology (UTAUT) (Venkatesh, Morris, Davis, \& Davis, 2003). Even though TAM was first introduced to understand the adoption of new technology by employees within the organization, then the model is suitable to explain the adoption of new technology by consumers or any other end-users (Natarajan, Balasubramanian, \& Kasilingam, 2018). TAM is the most vigorous and commonly used one to understand the adoption and acceptance of new technology (Chen, Gillenson, \& Sherrell, 2002). Because TAM explains the variance of intention to use to a considerable extent (40\%) by demonstrated many empirical types of researches (Venkatesh, \& Davis, 2000). TAM is adapted from TRA and its objective is to clarify determinants of new technology acceptance (Davis, Bagozzi, \& Warshaw, 1989). Based on TAM, perceived usefulness and perceived ease of use are the drivers for new technology acceptance (Davis, 1989). Perceived usefulness is how much an individual believes that utilizing a specific information technology will improve his execution and perceived ease of use is how much an individual believes that using particular information technology will be effortless (Dutot, 2015). Furthermore, since if a technology 
is used easily it will be more useful, perceived ease of use influence perceived usefulness (Gu, Lee, \& Suh, 2009, Lee et al., 2018). Two beliefs perceived usefulness and perceived ease of use about the new technology influence attitude toward this technology (Davis, Bagozzi, \& Warshaw, 1989). Attitude is evaluation and opinion on whether a behavior is good or bad (Verma, \& Sinha, 2018). Therefore, the attitude determines the intention to do or not to do the behavior in question. Consequently, attitude culminates in intention to use according to TAM (Davis, Bagozzi, \& Warshaw, 1989). To understand the usage intention of individuals in more details, there is a need to know the factors which affect their two beliefs aforementioned. On account of a better understanding of critical determinants, the user's intention to use the new technology can be better explained (Venkatesh, \& Davis, 2000). Furthermore, these determinants can provide leverage factors to enhance positive perceptions and as a consequence of user acceptance (Venkatesh, 2000). Therefore, this paper examines the original TAM model by adding technology anxiety, technology self-efficacy, compatibility and knowledge as possible determinants based on related literature and the nature of self-checkout systems.

\subsection{Technology anxiety}

Technology anxiety is the negative feelings of individuals when they are confronted with the necessity to use technology (Sánchez-Prieto, Olmos-Migueláñez, \& García-Peñalvo, 2017). This relates to individual's general perceptions about technology use (Venkatesh, 2000). It has been dealt with in various studies where technology anxiety is very common and therefore stands out as an important factor to be understood (Meuter, Ostrom, Bitner, \& Roundtree, 2003). If individuals feel anxious about using technology, they cannot perceive it as easy to use (Demoulin, \& Djelassi, 2016). The reason is that anxiety is a strong emotion affecting beliefs, attitudes, and behavior. Because technology anxiety is a feeling of the state of noncomfort when using technology and constitutes an impediment to the adoption of new technology (Park, Ahn, Thavisay, \& Ren, 2019). However, as the experience increases, its negative effects may be reduced (Venkatesh, \& Bala, 2008). Even though individuals are more curious about self-service technologies and aware of their benefits, they can avoid using selfservice technologies if they are not comfortable with using new technology (Meuter, Ostrom, Bitner, \& Roundtree, 2003). Hence, it is expected that technology anxiety causes negative perceptions about the ease of use and usefulness of self-checkout systems. Based on these arguments, the following hypotheses are posited:

H1- Technology anxiety is negatively related to perceived ease of use.

H2- Technology anxiety is negatively related to perceived usefulness.

\subsection{Technology self-efficacy}

Technology self-efficacy is a self-belief of an individual about own ability to use technology without any problem (Venkatesh, 2000). Self-efficacy consists of the estimation of result and estimation of efficacy; the former is individual's estimation about that own act reach a result and the latter is individual's estimation about that own ability to reach the desired result (Chen, Chen, and Yen, 2011). Self-efficacy has a significant impact on the emotional reactions of individuals (Compeau, \& Higgins, 1995). Some individuals may believe that they can use new technology easily, whereas some may believe that they don't have the ability to learn how to use it (Bailey, Pentina, Mishra, \& Ben Mimoun, 2017). This is closely related to the degree of technology self-efficacy they have. Individuals tend to prefer the behaviors they think they can, while they tend to stay away from the behaviors, they think they cannot (Compeau, \& Higgins, 1995). In that vein, they think about self-checkout systems as useful, if and only if they can use self-checkout systems without having a problem. Because in case they believe that there will be a problem when using self-checkout systems, they may believe that using self-checkout systems is not only useless but also problematical. Moreover, self-checkout systems will be perceived as easy to use when self-efficacy is high since selfefficacy is an individual's trust in own ability to achieve an action (Sánchez, \& Hueros, 2010). That is, having a high-level self-belief about understanding to use self-checkout systems may lead to that individual perceive it positively in terms of usage and usefulness. Hence, the following hypotheses are posited:

H3- Technology self-efficacy is positively related to perceived ease of use.

H4- Technology self-efficacy is positively related to perceived usefulness.

\subsection{Compatibility}

Compatibility refers to the degree of perception about that new technology is accordant with the individual's values, experiences, and needs (Ozturk, Bilgihan, Nusair, \& Okumus, 2016). Namely, it is composed of perceptions about the suitability of a certain technology with individual's needs and lifestyle (Jaklič, Grublješič, \& Popovič, 2018). When individuals are confronted with new technology, they can pass judgment on it according to their perception about that this new technology is whether compatible with their needs, lifestyles and experiences or not (Cheng, 2015). Therefore, high compatibility perception with the needs and lifestyles of individuals will accelerate the adaptation of them to new technology (Schmidthuber, Maresch, \& Ginner, 2018). From the self-checkout system as self-service technology, time-saving is one of the main benefits seen by users (Meuter, Ostrom, Bitner, \& Roundtree, 2003) and it can be a need for them. Thus, they will perceive the self-checkout system compatible and to benefit themselves. Moreover, the self-checkout system will be compatible with the individual's lifestyle who previously used any self-service technology. Since they are not unfamiliar with such technologies, they will perceive easy to understand the use of the self-checkout system. Besides, they can believe that the self-checkout system is 
advantageous for them if they think that the self-checkout system is compatible with their needs. Based on these arguments, the following hypotheses are posited:

H5- Compatibility is positively related to perceived ease of use.

H6- Compatibility is positively related to perceived usefulness.

\subsection{Knowledge}

Knowledge helps individuals better use technology and more efficiently (Liu, \&Tai, 2016). Therefore, perceptions of new technology are related to the individual's degree of knowledge about technology. Moreover, more knowledgeable individuals can understand how a specific technology can do many things possible for own tasks and what the advantages (Liu, \&Tai, 2016). Knowledge of technology allows individuals to understand what they can do with that technology and what advantages they may have by using it (Liu, \&Tai, 2016). Individuals knowing a certain technology have no difficulty in adapting to its usage since knowledge gives them confidence in using technology in question with its different features (Kim, Mirusmonov, \& Lee, 2010). Thereby, people with knowledge about self-service technologies likely perceive the self-checkout system as user-friendly, whereas people who don't have enough knowledge may perceive it as complicated and inconvenience. No matter what it benefits, people without knowledge may not be persuaded to believe that self-checkout system is favorable and easy to handle technology. Hence, individuals, who are highly knowledgeable in technology, don' find it difficult to use and also, they can use this technology easily and efficiently (Liu, \&Tai, 2016). Namely, people who have knowledge about selfcheckout systems will not hesitate to use self-checkout systems because they will be aware both that its usage is not difficult and that its use can bring many benefits to them. Based on these arguments, the following hypotheses are posited:

H7- Self-checkout system knowledge is positively related to perceived ease of use.

H8-Self-checkout system knowledge is positively related to perceived usefulness.

\subsection{Perceived ease of use and perceived usefulness}

Individuals tend to use technology if they perceive it as useful and easy to use (Gu, Lee, \& Suh, 2009). This disposition is based on TAM. TAM assumes that two beliefs perceived usefulness and perceived ease of use are the drivers for new technology acceptance (Davis, Bagozzi, \& Warshaw, 1989). In a sense, when a new technology is perceived as useful and easy to use then it will be preferred and used increasingly (Gu, Lee, \& Suh, 2009). Furthermore, according to TAM, perceived ease of use enhances perceived usefulness and these two beliefs have an influence on attitude (Davis, Bagozzi, \& Warshaw, 1989). When a technology is used with ease, individual perceptions about its benefits will be in a positive direction $(\mathrm{Gu}, \mathrm{Lee}, \&$ Suh, 2009). Because of self-checkout systems, if individuals perceive it as easy to use, they will think that it is advantageous. Moreover, when people perceive self-checkout systems as user-friendly, they exhibit a positive attitude toward it. In other respects, if self-checkout systems are seen as favorable, individuals will approach it positively because of its potential to benefit them. Hence, the following hypotheses are posited:

H9-Perceived ease of use is positively related to attitude toward self-checkout systems.

H10-Perceived usefulness is positively related to attitude toward self-checkout systems.

\subsection{Attitude}

TAM suggests that attitude is the determinant of intention to use (Davis, Bagozzi, \& Warshaw, 1989). Attitude is related to subjective evaluations of behavior. Therefore, negative evaluations will cause to avoid to do that behavior, while positive evaluations will trigger a desire to do that behavior (Groß, 2018). In other words, the direction of attitude determines the formation of an intention to use. If individuals have a favorable evaluation about the use of self-checkout systems, they are expected to look at this behavior positively and being willingness to use self-checkout systems. On the contrary, people who have a negative attitude about self-checkout systems, do not want to use it and avoid using it as much as possible. Based on these arguments and typical TAM, the following hypothesis is posited:

H11-Attitude toward self-checkout systems is positively related to intention to use.

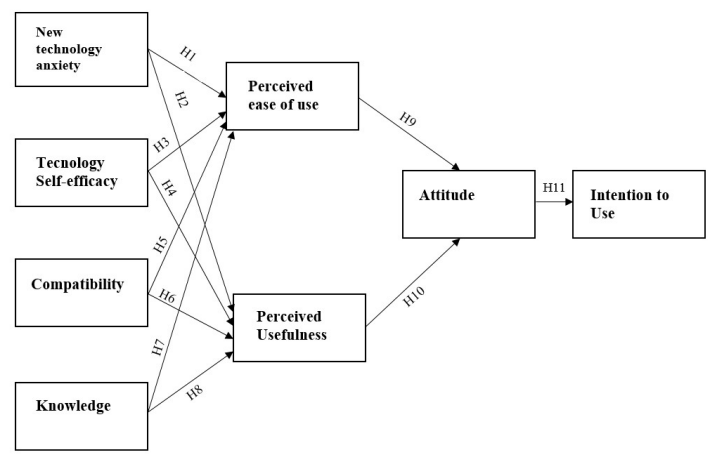

Fig. 1. Research Model 


\section{Research method and analysis}

\subsection{Measures}

The survey method was employed in this study and multi-item scales were adapted from previous studies by modifications to reflect the context of self-checkout systems. New technology anxiety scale was adapted from Bailey, Pentina, Mishra, and Ben Mimoun (2017). Scale items for technology self-efficacy were adapted from Bailey, Pentina, Mishra, and Ben Mimoun (2017) who used the items from Schwarzer, and Jerusalem (1995). Scales for compatibility, knowledge, perceived ease of use and perceived usefulness were adapted from Kim, Mirusmonov, and Lee (2010). All that's just mentioned were measured by seven-point Likert scale. Attitude and intention to use scales were adapted from Bailey, Pentina, Mishra, and Ben Mimoun (2017). These two were measured by the seven-point semantic differential scale. The survey items originally in English, translated into Turkish and then re-translated into English using the parallel translation method. Thus, it was ensured the accuracy of translated items. The preliminary version of our survey was evaluated by experts in terms of ambiguities and meaningfulness of survey items and also a pilot test was conducted with 30 participants they use self-checkout systems before. Subsequently, the questionnaire was revised and finalized based on their feedbacks. This procedure was ensured that the scales had content and face validity.

\subsection{Sample and Data Collection}

The data was gathered through an online survey employed among individuals who live in Istanbul in Turkey. Turkey is a developing country and Istanbul is the largest city where technological innovations are used most and adapted quickly in Turkey. The other reason to select Istanbul to conduct our research is that more than 90 percent of SCS supermarkets have been in Istanbul. The population of the city is 18 million ( $23 \%$ of the country total population) and the population of the city increases in working hours, because of the people visiting from different cities of the country for trade and tourism. Our sample consists of individuals who used self-checkout system at least once. Because this is most suitable for our research. According to this purpose, after data collection responses were checked and some of them discarded since participants did not use the self-checkout systems before. Finally, a total of 281 responses were deemed to be valid and usable for this study. The demographic profile of our sample is shown in Table 1.

Table 1

Demographic profile of sample

\begin{tabular}{lll}
\hline Demographic variable & Frequency & Percent (\%) \\
\hline Gender & 158 & 56.2 \\
Male & 123 & 43.8 \\
Female & & \\
\hline Education & 6 & 2.1 \\
Primary school & 28 & 10.0 \\
Secondary /High school & 189 & 67.3 \\
University & 58 & 20.6 \\
Master's/Doctoral degree & & \\
\hline Using Frequency & 83 & \\
Several days a month & 126 & 29.5 \\
Rarely & 60 & 44.8 \\
Several days a week & 10 & 21.4 \\
Everyday & & 3.6 \\
\hline
\end{tabular}

\subsection{Common Method Variance Assessment}

Common method bias was tested using Harman's single-factor test due to the likelihood of being common factor (Podsakoff, MacKenzie, Lee \& Podsakoff, 2003). Accordingly, EFA by using unrotated principal components analysis with varimax rotation was performed. It was found that all the factors have eigenvalues greater than 1 and there was no single factor that accounts for most of the total variances (highest variance accounted for roundly $44 \%$ of the total variance). It indicated that our investigation is not prone to have a common method bias concern.

\subsection{Validity and Reliability}

After data collection, firstly exploratory factor analysis (EFA) was conducted to check whether the data were suitable for factor analysis. Kaiser-Meyer-Olkin (KMO) measure was .93 which indicates the sampling adequacy and Bartlett's test of sphericity was significant $\left(\mathrm{x}^{2}=7275.980, \mathrm{p}=.00\right)$ which indicates the suitability of data for factor analysis. Next, confirmatory factor analysis (CFA) was conducted using AMOS to analyze factor structure. All 8 variables were tested in one CFA model. Results indicated an adequate model fit $\left(\chi^{2 / \mathrm{df}}=2,566\right.$, CFI: .911, IFI: .911, TLI: .898, RMSEA: .075). Table 2 shows the factor loadings, validity and reliability estimates. According to these results, each item loaded significantly on their respective variables. The values of average variance extracted (AVE) for all variables exceed 0.5 and composite reliabilities (CR) for all variables exceed 0.7 which are minimum value acceptable (Fornell, \& Larcker 1981). These findings show that convergent 
validity is present. Also, Cronbach's alpha coefficient for all variables exceeds 0.7 (Nunnally, 1978). It indicates that measures are reliable and coherent internally.

Table 2

The Results of CFA

\begin{tabular}{|c|c|c|c|c|c|}
\hline Variables & Items & Factor Loadings & Cronbach's $\alpha$ & AVE & $\mathbf{C R}$ \\
\hline \multirow{4}{*}{ Technology anxiety } & TA4 & .84 & \multirow{4}{*}{.85} & \multirow{4}{*}{.59} & \multirow{4}{*}{.85} \\
\hline & TA3 & .79 & & & \\
\hline & TA2 & .76 & & & \\
\hline & TA1 & .67 & & & \\
\hline \multirow{3}{*}{ Technology self-efficacy } & SE7 & .59 & \multirow{3}{*}{.81} & \multirow{3}{*}{.62} & \multirow{3}{*}{.82} \\
\hline & SE6 & .88 & & & \\
\hline & SE5 & .85 & & & \\
\hline \multirow{3}{*}{ Compatibility } & $\mathrm{C} 10$ & .68 & \multirow{3}{*}{.83} & \multirow{3}{*}{.65} & \multirow{3}{*}{.85} \\
\hline & C9 & .86 & & & \\
\hline & $\mathrm{C} 8$ & .86 & & & \\
\hline \multirow{4}{*}{ Knowledge } & K14 & .84 & \multirow{4}{*}{.81} & \multirow{4}{*}{.52} & \multirow{4}{*}{.81} \\
\hline & K13 & .60 & & & \\
\hline & $\mathrm{K} 12$ & .71 & & & \\
\hline & K11 & .70 & & & \\
\hline \multirow{3}{*}{ Perceived usefulness } & PU17 & .85 & \multirow{3}{*}{.90} & \multirow{3}{*}{.75} & \multirow{3}{*}{.90} \\
\hline & PU16 & .92 & & & \\
\hline & PU15 & .83 & & & \\
\hline \multirow{5}{*}{ Perceived ease of use } & PEOU18 & .85 & \multirow{5}{*}{.89} & \multirow{5}{*}{.64} & \multirow{5}{*}{.90} \\
\hline & PEOU19 & .78 & & & \\
\hline & PEOU20 & .82 & & & \\
\hline & PEOU21 & .90 & & & \\
\hline & PEOU22 & .63 & & & \\
\hline \multirow{6}{*}{ Attitude } & A23 & .88 & \multirow{6}{*}{.94} & \multirow{6}{*}{.71} & \multirow{6}{*}{.94} \\
\hline & A24 & .83 & & & \\
\hline & A25 & .82 & & & \\
\hline & A26 & .84 & & & \\
\hline & A27 & .84 & & & \\
\hline & A28 & $\begin{array}{l}.04 \\
.84\end{array}$ & & & \\
\hline \multirow{3}{*}{ Intention to use } & IU29 & .93 & \multirow{3}{*}{.95} & & \\
\hline & IU30 & .98 & & .86 & .95 \\
\hline & IU31 & .87 & & & \\
\hline
\end{tabular}

\subsection{Hypothesis Testing and Results}

Structural equation modeling (SEM) analysis was conducted to test the hypotheses using AMOS. First, intercorrelations were reviewed to examine the relationships among all dependent and independent variables. Table 3 presents the descriptive statistics and correlation coefficients of our measures.

\section{Table 3}

Correlations and Descriptive Statistics

\begin{tabular}{|c|c|c|c|c|c|c|c|c|}
\hline Variables & 1 & 2 & 3 & 4 & 5 & 6 & 7 & 8 \\
\hline Technology anxiety & 1 & & & & & & & \\
\hline Technology self-efficacy & -.41 & 1 & & & & & & \\
\hline Compatibility & -.25 & .69 & 1 & & & & & \\
\hline Knowledge & -.53 & .79 & .63 & 1 & & & & \\
\hline Perceived usefulness & -.36 & .60 & .57 & .90 & 1 & & & \\
\hline Perceived ease of use & -.50 & .83 & .63 & .96 & .79 & 1 & & \\
\hline Attitude & -.40 & .47 & .52 & .72 & .74 & .59 & 1 & \\
\hline Intention to use & -.33 & .29 & .34 & .51 & .50 & .43 & .64 & 1 \\
\hline Means & 2.68 & 5.94 & 5.78 & 5.39 & 5.87 & 5.82 & 5.81 & 6.11 \\
\hline Std. Dev. & 1.39 & 1.26 & 1.23 & 1.27 & 1.23 & 1.12 & 1.09 & 1.19 \\
\hline
\end{tabular}

\section{Table 4}

Path Model

\begin{tabular}{llll}
\hline HYPOTHESES & PATH & PATH COEFFICIENT & RESULT \\
\hline H1 & Technology anxiety $\rightarrow$ Perceived ease of use & .002 & .105 \\
H2 & Technology anxiety $\rightarrow$ Perceived usefulness & $.283^{* *}$ & Not Supported \\
H3 & Technology self- efficacy $\rightarrow$ Perceived ease of use & $.314^{* *}$ & Supported \\
H4 & Technology self- efficacy $\rightarrow$ Perceived usefulness & -.026 & Supported \\
H5 & Compatibility $\rightarrow$ Perceived ease of use & $.146^{*}$ & Not Supported \\
H6 & Compatibility $\rightarrow$ Perceived usefulness & $.738^{* *}$ & Supported \\
H7 & Knowledge $\rightarrow$ Perceived ease of use & $1.099^{* *}$ & .02 \\
H8 & Knowledge $\rightarrow$ Perceived usefulness & $.735^{* *}$ & Supported \\
H9 & Perceived ease of use $\rightarrow$ Attitude & $.645^{* *}$ \\
H10 & Perceived usefulness $\rightarrow$ Attitude & Not Supported \\
H1 & Attitude $\rightarrow$ Intention to use & Supported & Supported \\
\hline
\end{tabular}


Table 4 shows that research model fits well to data gathered $\left(\chi^{2} / \mathrm{df}=2.565\right.$, CFI: .908, IFI: .909, TLI: .898, RMSEA: .075). Table 4 also reveals the results of hypotheses testing. The result shows that technology anxiety is not related to both perceived ease of use $(\beta=.002, p>.05)$ and perceived usefulness $(\beta=.105, \mathrm{p}>.05)$. Therefore, $\mathrm{H} 1$ and $\mathrm{H} 2$ are not supported. Regarding $\mathrm{H} 3$ and $\mathrm{H} 4$, we have found that technology self- efficacy is related to perceived ease of use $(\beta=.283, \mathrm{p}<.01)$ and also related to perceived usefulness $(\beta=.314, \mathrm{p}<.01)$, supporting $\mathrm{H} 3$ and $\mathrm{H} 4$. Compatibility is related to perceived usefulness $(\beta=.146$, $\mathrm{p}<.05)$, while it is not related to perceived ease of use $(\beta=-.026, \mathrm{p}>.05)$. So, H6 is supported, but H5 is not. Besides, knowledge is associated with both perceived ease of use $(\beta=.738, \mathrm{p}<.01)$ and perceived usefulness $(\beta=1.099, \mathrm{p}<.01)$, supporting $\mathrm{H} 7$ and $\mathrm{H} 8$. We also find that perceived usefulness is related to attitude $(\beta=.735, \mathrm{p}<.01)$ but perceived ease of use is not $(\beta=.02, \mathrm{p}>.05)$. While H10 is supported, H9 is not supported. Moreover, attitude is associated with intention to use $(\beta=.645, p<.01)$, supporting H11.

\section{Discussion and implications}

This paper aims to offer a contribution to the literature by exploring the factors that affect the acceptance of self-checkout systems. In this respect, the research is conducted in Istanbul city in Turkey by incorporating technology anxiety, technology self-efficacy, compatibility and knowledge to the original TAM model. Thus, this study offers both theoretical and practical contributions. The empirical results illustrate that perceived usefulness influences attitude toward self-checkout systems and also attitude positively influences intention to use. These findings are consistent with past researches using the TAM model (Chen, Gillenson, \& Sherrell, 2002; Liébana-Cabanillas, Sánchez-Fernández, \& Muñoz-Leiva, 2014; Verma, \& Sinha, 2018). In other respect, the effect of perceived ease of use on attitude is insignificant. This is inconsistent with original TAM. However, in the literature, similar results are found in some studies (Lu, Hsu, \& Hsu, 2005). It can be considered that the selfcheckout system is seen as user-friendly and not a complex system already and thus perceived ease of use has not an impact on attitude toward it. Namely, when individuals think that self-checkout system is beneficial, their positive attitudes are triggered. Also, positive evaluations about the self-checkout systems and usage of it provide the willing to use it. As implied by these findings, managers should focus on the benefits of self-checkout systems and emphasize the all possible values which are added by using this innovative technology for customers. For this purpose, many types of advertisements may be used to clarify and publicize the advantages of using self-checkout systems. Customer satisfaction survey results and their opinions about using it may be a predominant way to convince them. In this respect, social media should be used in particular as an important tool to announce to everyone. Thus, the positive perceptions of customers about the advantages of using self-checkout systems can be possible to enhance. On the other hand, it is crucial that the self-checkout system stays as a preference. If it is the only option for payment, customers can get used to it. Therefore, they may not realize the value of its benefits, as they cannot make a comparison with the cashier-staffed payment system. The results demonstrate technology self-efficacy, compatibility, and knowledge are positively related to perceived usefulness. Also, technology self-efficacy and knowledge are associated with perceived ease of use. These findings support previous studies (Gu, Lee, \& Suh, 2009; Kim, Mirusmonov, \& Lee, 2010; Jin, 2014; Oh, \& Yoon, 2014; Sánchez-Prieto, Olmos-Migueláñez, \& García-Peñalvo, 2017). However, it is found that technology anxiety is associated with neither perceived ease of use nor perceived usefulness. This result is inconsistent with many studies (Brown, 2002; Kim, \& Forsythe, 2010; Chuo, Tsai, Lan, \& Tsai, 2011; Gelbrich, \& Sattler, 2014; Tsai, Cheng, Tsai, Hung, \& Chen, 2019) and also in line with a few studies (Abdullah, Ward, \& Ahmed, 2016). It may be because our sample consisted of individuals who used the self-checkout system at least once. Therefore, the possible effect of technology anxiety may not have been effective in our study because of all of our sample were already users and accordingly may have no anxiety. These results suggest that individuals with knowledge about self-checkout systems and who believe that can use it without any problem are aware of its benefits. They also perceive that it is easy to use. Furthermore, the suitability of self-checkout systems with individuals life-styles is an important factor that affects their ideas to whether it is advantageous or not. According to these results, managers should be aware of the user's knowledge, competence, and lifestyle. Because only the actions developed by taking into consideration of these factors can be effective in the perception of customers. Accordingly, there should be a staff member to assist customers. Furthermore, in-store posters which give information about how to use it such as user guide should be present. In-store videos also may be influential to inform and convince that they can use it. Publicization of online tutorial and online video which enlighten the usage information and details may also useful to enhance positive perceptions of customers who do not want to waste time reviewing the in-store posters or video during shopping.

\section{Conclusion}

This study has attempted to reveal what factors may affect intention to use self-checkout systems by incorporating technology anxiety, self-efficacy, knowledge, and compatibility into TAM. The research results suggest that technology self-efficacy and knowledge were related to both perceived ease of use and perceived usefulness. Compatibility is positively related to perceived usefulness. Moreover, the findings support and reveal the links of perceived usefulness-attitude and attitude-intention to use based on original TAM. By extending related studies and fill research gaps, this study provides deep knowledge, awareness and new insights for researchers. Furthermore, the results enable the firms to understand the expectations of SCS customers. This study offers some recommendations and clues to the top management of the firms to develop corrective and curative actions. 


\section{Limitations and further research}

There are some methodological constraints in this study. First, this study represents a snapshot in time, as with all other all cross-sectional researches. While the conditions under which the data were gathered will probable to remain the same, this is not guaranteed and conditions may change. Second, the sample consisted of individuals who used the self-checkout system at least once. Therefore, the results do not provide information about non-users' acceptance of it. Third, this study is conducted in a particular place, Istanbul in Turkey. Thus, results may show an alteration in case it employed in different domains. Namely, generalizability is a constraint for this study. Despite the limitations aforementioned, this study offers new insights for future studies. In this research, original TAM was examined by adding technology anxiety, technology self-efficacy, compatibility and knowledge as determinants in the context of the intention to use self-checkout systems. Researches can examine determinants of the intention to use self-checkout systems by integrating other models such as TRA and UTAUT with TAM. Additionally, in future studies, the same model can be tested in different domains or age groups and even a comparative study can be conducted. Further studies may investigate the moderator roles of demographic variables by adding them to our model. Future research may also examine this in both developing and developed countries and compare the results. Moreover, cultural differences may be considered in the next studies. It may also valuable and essential to have a complete picture about determinants of intention to use self-checkout systems by examining how these relationships change over time because of increased experience.

\section{Declaration}

- Availability of data and material: Authors prefer to use the data as another data article later, this is the reason why data is unavailable.

- Competing interests: The authors declare that they have no competing interests.

- Funding: No funding resource.

- Authors' contributions: UC and AE designed the survey, collected the necessary data, UC, AE, and HT analyzed the finding, read and approved the final manuscript.

- Acknowledgments: Not available.

\section{References}

Abdullah, F., Ward, R., \& Ahmed, E. (2016). Investigating the influence of the most commonly used external variables of TAM on students' Perceived Ease of Use (PEOU) and Perceived Usefulness (PU) of e-portfolios. Computers in Human Behavior, 63, 75-90.

Ajzen, I. (1991). The theory of planned behavior. Organizational Behavior and Human Decision Processes, 50(2), $179-211$.

Akour, I. A., \& Dwairi, M. A. (2011). Testing technology acceptance model in developing countries: The case of Jordan. International Journal of Business and Social Science, 2(14).278-284.

Bailey, A. A., Pentina, I., Mishra, A. S., \& Ben Mimoun, M. S. (2017). Mobile payments adoption by US consumers: an extended TAM. International Journal of Retail \& Distribution Management, 45(6), 626-640.

Brown, I. T. (2002). Individual and technological factors affecting perceived ease of use of web-based learning technologies in a developing country. The Electronic Journal of Information Systems in Developing Countries, 9(1), 1-15.

Bulmer, S., Elms, J., \& Moore, S. (2018). Exploring the adoption of self-service checkouts and the associated social obligations of shopping practices. Journal of Retailing and Consumer Services, 42, 107-116.

Chen, L., Gillenson, M. L., \& Sherrell, D. L. (2002). Enticing online consumers: A technology acceptance perspective. Information \& Management, 39(8), 705-719.

Chen, K., Chen, J. V., \& Yen, D. C. (2011). Dimensions of self-efficacy in the study of smart phone acceptance. Computer Standards \& Interfaces, 33(4), 422-431.

Cheng, Y. M. (2015). Towards an understanding of the factors affecting m-learning acceptance: Roles of technological characteristics and compatibility. Asia Pacific Management Review, 20(3), 109-119.

Chipp, K., Hoenig, S. \& Nel, D. (2006). What can industrializing countries do to avoid the need for marketing reform?. In Sheth, J.N. \& Sisodia, R.S., Does Marketing Need Reform?: Fresh Perspectives on the Future. New York: M.E. Sharpe.

Chuo, Y. H., Tsai, C. H., Lan, Y. L., \& Tsai, C. S. (2011). The effect of organizational support, self efficacy, and computer anxiety on the usage intention of e-learning system in hospital. African Journal of Business Management, 5(14), 55185523.

Collier, J. E., Moore, R. S., Horky, A., \& Moore, M. L. (2015). Why the little things matter: Exploring situational influences on customers' self-service technology decisions. Journal of Business Research, 68(3), 703-710.

Compeau, D. R., \& Higgins, C. A. (1995). Computer self-efficacy: Development of a measure and initial test. MIS Quarterly, 19(2), 189-211.

Curran, J. M., Meuter, M. L., \& Surprenant, C. F. (2003). Intentions to use self-service technologies: a confluence of multiple attitudes. Journal of Service Research, 5(3), 209-224.

Davis, F. D. (1989). Perceived usefulness, perceived ease of use, and user acceptance of information technology. MIS quarterly, 13(3), 319-340.

Davis, F. D., Bagozzi, R. P., \& Warshaw, P. R. (1989). User acceptance of computer technology: a comparison of two theoretical models. Management science, 35(8), 982-1003. 
Demoulin, N. T., \& Djelassi, S. (2016). An integrated model of self-service technology (SST) usage in a retail context. International Journal of Retail \& Distribution Management, 44(5), 540-559.

Dutot, V. (2015). Factors influencing near field communication (NFC) adoption: An extended TAM approach. The Journal of High Technology Management Research, 26(1), 45-57.

Fishbein, M., \& Ajzen, I. (1975). Belief, attitude, intention and behavior: An introduction to theory and research. Reading, MA: Addison-Wesley.

Fornell, C., \& Larcker, D. F. (1981). Evaluating structural equation models with unobservable variables and measurement error. Journal of Marketing Research, 18(1), 39-51.

Gelbrich, K., \& Sattler, B. (2014). Anxiety, crowding, and time pressure in public self-service technology acceptance. Journal of Services Marketing, 28(1), 82-94.

Groß, M. (2018). Heterogeneity in consumers' mobile shopping acceptance: A finite mixture partial least squares modelling approach for exploring and characterising different shopper segments. Journal of Retailing and Consumer Services, 40, 8-18.

Gu, J. C., Lee, S. C., \& Suh, Y. H. (2009). Determinants of behavioral intention to mobile banking. Expert Systems with Applications, 36(9), 11605-11616.

Jaklič, J., Grublješič, T., \& Popovič, A. (2018). The role of compatibility in predicting business intelligence and analytics use intentions. International Journal of Information Management, 43, 305-318.

Jin, C. H. (2014). Adoption of e-book among college students: The perspective of an integrated TAM. Computers in Human Behavior, 41, 471-477.

Kallweit, K., Spreer, P., \& Toporowski, W. (2014). Why do customers use self-service information technologies in retail? The mediating effect of perceived service quality. Journal of Retailing and Consumer Services, 21(3), 268-276.

Kim, C., Mirusmonov, M., \& Lee, I. (2010). An empirical examination of factors influencing the intention to use mobile payment. Computers in Human Behavior, 26(3), 310-322.

Kim, J., \& Forsythe, S. (2010). Factors affecting adoption of product virtualization technology for online consumer electronics shopping. International Journal of Retail \& Distribution Management, 38(3), 190-204.

Kim, M., \& Qu, H. (2014). Travelers' behavioral intention toward hotel self-service kiosks usage. International Journal of Contemporary Hospitality Management, 26(2), 225-245.

Larson, R. B. (2019). Supermarket self-checkout usage in the United States. Services Marketing Quarterly, 40(2), 141-156.

Lee, H. J., \& Yang, K. (2013). Interpersonal service quality, self-service technology (SST) service quality, and retail patronage. Journal of Retailing and Consumer Services, 20(1), 51-57.

Lee, H. J., \& Lyu, J. (2016). Personal values as determinants of intentions to use self-service technology in retailing. Computers in Human Behavior, 60, 322-332.

Lee, J., Kim, J., \& Choi, J. Y. (2019). The adoption of virtual reality devices: The technology acceptance model integrating enjoyment, social interaction, and strength of the social ties. Telematics and Informatics, 39, 37-48.

Leung, L. S. K., \& Matanda, M. J. (2013). The impact of basic human needs on the use of retailing self-service technologies: A study of self-determination theory. Journal of Retailing and Consumer Services, 20(6), 549-559.

Liébana-Cabanillas, F., Sánchez-Fernández, J., \& Muñoz-Leiva, F. (2014). Antecedents of the adoption of the new mobile payment systems: The moderating effect of age. Computers in Human Behavior, 35, 464-478.

Liu, S. (2012). The impact of forced use on customer adoption of self-service technologies. Computers in Human Behavior, 28(4), 1194-1201.

Liu, G. S., \& Tai, P. T. (2016). A Study of Factors Affecting the Intention to Use Mobile Payment Services in Vietnam. Economics, 4(6), 249-273.

Lu, H. P., Hsu, C. L., \& Hsu, H. Y. (2005). An empirical study of the effect of perceived risk upon intention to use online applications. Information Management \& Computer Security, 13(2), 106-120.

Meuter, M. L., Ostrom, A. L., Roundtree, R. I., \& Bitner, M. J. (2000). Self-service technologies: understanding customer satisfaction with technology-based service encounters. Journal of Marketing, 64(3), 50-64.

Meuter, M. L., Ostrom, A. L., Bitner, M. J., \& Roundtree, R. (2003). The influence of technology anxiety on consumer use and experiences with self-service technologies. Journal of Business Research, 56(11), 899-906.

Natarajan, T., Balasubramanian, S. A., \& Kasilingam, D. L. (2018). The moderating role of device type and age of users on the intention to use mobile shopping applications. Technology in Society, 53, 79-90.

Nunnally, J. C. (1978). Psychometric Theory. $2^{\text {nd }}$ ed., McGraw-Hill Series in Psychology), New York, McGraw-Hill.

Oghazi, P., Mostaghel, R., Hultman, M., \& Parida, V. (2012). Antecedents of technology-based self-service acceptance: a proposed model. Services Marketing Quarterly, 33(3), 195-210.

Oh, J., \& Yoon, S. J. (2014). Validation of haptic enabling technology acceptance model (HE-TAM): Integration of IDT and TAM. Telematics and Informatics, 31(4), 585-596.

Orel, F. D., \& Kara, A. (2014). Supermarket self-checkout service quality, customer satisfaction, and loyalty: Empirical evidence from an emerging market. Journal of Retailing and Consumer Services, 21(2), 118-129.

Ozturk, A. B., Bilgihan, A., Nusair, K., \& Okumus, F. (2016). What keeps the mobile hotel booking users loyal? Investigating the roles of self-efficacy, compatibility, perceived ease of use, and perceived convenience. International Journal of Information Management, 36(6), 1350-1359.

Park, J., Ahn, J., Thavisay, T., \& Ren, T. (2019). Examining the role of anxiety and social influence in multi-benefits of mobile payment service. Journal of Retailing and Consumer Services, 47, 140-149 
Podsakoff, P. M., MacKenzie, S. B., Lee, J. Y., \& Podsakoff, N. P. (2003). Common method biases in behavioral research: a critical review of the literature and recommended remedies. Journal of Applied Psychology, 88(5), 879-903.

Sánchez, R. A., \& Hueros, A. D. (2010). Motivational factors that influence the acceptance of Moodle using TAM. Computers in human behavior, 26(6), 1632-1640.

Sánchez-Prieto, J. C., Olmos-Migueláñez, S., \& García-Peñalvo, F. J. (2017). MLearning and pre-service teachers: An assessment of the behavioral intention using an expanded TAM model. Computers in Human Behavior, 72, 644-654.

Schliewe, J., \& Pezoldt, K. (2010). A cross-cultural comparison of factors influencing self-scan checkout use. Journal of Business \& Economics Research, 8(10), 39-47.

Schmidthuber, L., Maresch, D., \& Ginner, M. (2018). Disruptive technologies and abundance in the service sector-toward a refined technology acceptance model. Technological Forecasting and Social Change.

Tsai, J. M., Cheng, M. J., Tsai, H. H., Hung, S. W., \& Chen, Y. L. (2019). Acceptance and resistance of telehealth: The perspective of dual-factor concepts in technology adoption. International Journal of Information Management, 49, 34-44.

Venkatesh, V. (2000). Determinants of perceived ease of use: Integrating control, intrinsic motivation, and emotion into the technology acceptance model. Information Systems Research, 11(4), 342-365.

Venkatesh, V., \& Davis, F. D. (2000). A theoretical extension of the technology acceptance model: Four longitudinal field studies. Management Science, 46(2), 186-204.

Venkatesh, V., Morris, M. G., Davis, G. B., \& Davis, F. D. (2003). User acceptance of information technology: Toward a unified view. Management Information Systems Quarterly, 27(3), 425-478.

Venkatesh, V., \& Bala, H. (2008). Technology acceptance model 3 and a research agenda on interventions. Decision sciences, 39(2), 273-315.

Verma, P., \& Sinha, N. (2018). Integrating perceived economic wellbeing to technology acceptance model: The case of mobile based agricultural extension service. Technological Forecasting and Social Change, 126, 207-216.

Wang, C., Harris, J., \& Patterson, P. (2013). The roles of habit, self-efficacy, and satisfaction in driving continued use of selfservice technologies: a longitudinal study. Journal of Service Research, 16(3), 400-414.

Weijters, B., Rangarajan, D., Falk, T., \& Schillewaert, N. (2007). Determinants and outcomes of customers' use of self-service technology in a retail setting. Journal of Service Research, 10(1), 3-21.

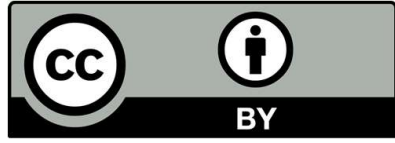

(C) 2020 by the authors; licensee Growing Science, Canada. This is an open access article distributed under the terms and conditions of the Creative Commons Attribution (CC-BY) license (http://creativecommons.org/licenses/by/4.0/). 